\title{
CIENTISTA POR UM DIA: A INICIAÇÃO À PESQUISA NA EDUCAÇÃO INFANTIL
}

\author{
Carla Melo da Silva ${ }^{1}$, Mônica da Silva Gallon ${ }^{2}$, Zulma Elizabete de Freitas Madruga ${ }^{3}$
}

\begin{abstract}
Resumo: O presente artigo relata uma prática realizada em uma turma de Pré I, na Educação Infantil, em uma instituição privada, na região metropolitana de Porto Alegre, RS, a fim de cumprir estágio supervisionado obrigatório, uma disciplina pertencente ao curso de Licenciatura em Pedagogia. Foram realizadas atividades práticas voltadas à digestão, educação alimentar e cuidados com higiene, observando à adequação da linguagem à faixa etária de cinco anos. A proposta teve por objetivo reconhecer os saberes prévios destes estudantes sobre o assunto e, por meio de perguntas geradas pelas atividades práticas a constituição de novos conhecimentos, proporcionando assim uma alfabetização científica. Após descrição da atividade, o trabalho apresenta uma análise sobre as reflexões realizadas com base na experiência vivida, apontando a importância do ensino de ciências desde os primeiros anos de escolarização bem como a formação adequada aos profissionais que atuam nesse segmento.
\end{abstract}

Palavras-chave: Ensino de Ciências, Educação Infantil, Formação de Professores.

\section{SCIENTIST FOR A DAY: THE INITIATION RESEARCH IN KINDERGARTEN}

\begin{abstract}
This article reports a practice carried in an early childhood education, in a private institution in the metropolitan region of Porto Alegre, to comply with a compulsory supervised internship, a course belonging to the Licentiate course in Pedagogy. Practical activities focused on digestion were done, nutrition education and care with hygiene, careful to adapt language to age five. the proposal recognized the prior knowledge of these students on the subject and, through questions generated by practical activities the creation of new knowledge, providing a scientific literacy. After description of the activity, the report presents an analysis of the reflections based on lived experience, pointing to the importance
\end{abstract}

1 Mestranda do Programa de Pós-Graduação em Educação em Ciências e Matemática da Pontifícia Universidade Católica do Rio Grande do Sul (PUCRS). Graduanda em Pedagogia pelo Centro Universitário Internacional (UNINTER). carlamelodasilva2015@gmail.com

2 Mestra e Doutoranda do Programa de Pós-Graduação em Educação em Ciências e Matemática da Pontifícia Universidade Católica do Rio Grande do Sul (PUCRS). Graduanda em Pedagogia pelo Centro Universitário Internacional (UNINTER). monica.gallon@gmail.com

3 Mestra e Doutora do Programa de Pós-Graduação em Educação em Ciências e Matemática da Pontifícia Universidade Católica do Rio Grande do Sul (PUCRS). Graduanda em Pedagogia pelo Centro Universitário Internacional (UNINTER). betefreitas.m@gmail.com 
of science education from the earliest years of schooling and adequate training to professionals in this segment.

Keywords: Science Teaching, Early Childhood Education, Teacher Education.

\section{INTRODUÇÃO}

A Educação Infantil (EI) há tempos vem buscando se desvincular da imagem de transferência dos cuidados da família para a escola. Historicamente, o surgimento das escolas de EI se deu pelas necessidades econômicas e sociais da sociedade. A professora era vista como a figura a qual se destinava as atenções e responsabilidades atribuídas à mãe: cuidar e educar. Entretanto, a dimensão educativa dessa fase é muito mais ampla. De acordo com Bujes (2001, p.17), "a criança deve ser vista como um sujeito que vive um momento em que predominam o sonho, a fantasia, a afetividade e as brincadeiras".

A Lei de Diretrizes e Bases da Educação Nacional (BRASIL, 1996, art. 29)4, enfatiza que nessa introdução à educação formal, estão previstos o desenvolvimento integral da criança "em seus aspectos físico, afetivo, intelectual, linguístico e social, complementando a ação da família e da comunidade". Nesse sentido, pais e/ou responsáveis têm importante papel na educação formal da criança e, portanto, devem estar atentos e serem conhecedores da proposta pedagógica que a escola apresenta. Para tanto, as Diretrizes Curriculares Nacionais da Educação Básica - DCNEB (BRASIL, 2013, p. 85), estabelecem que: "o estado necessita assumir sua responsabilidade na educação coletiva das crianças, complementando a ação das famílias”.

Essa lei também prevê que as pré-escolas e creches são responsáveis pelo cuidado e educação de crianças de zero a cinco anos, exigindo a atuação de profissionais com nível médio ou superior, por formação legalmente qualificada, abandonando a imagem assistencialista, porém, com vistas a atender às necessidades básicas de crianças dessa faixa etária (BRASIL, 2013). Como dever do Estado, a EI é posta na Constituição Federal de 1988 (BRASIL, 1988) ofertado em regime colaborativo e organizado em sistemas de ensino da União, dos Estados e Municípios (BRASIL, 2013), constituindo a primeira etapa da Educação Básica (LIBÂNEO et al., 2012; BRASIL, 2013). Nesse sentido, as Diretrizes expõem à autonomia das unidades de ensino no país na organização flexível do seu currículo, respeitando com as diversidades locais, empregando metodologias pedagógicas variadas, na condição de que estas assegurem à aprendizagem (BRASIL, 2013).

Como funções assumidas pelo Estado, para oferecimento de forma gratuita e de qualidade da EI:

4 Lei de Diretrizes e Bases - Lei no 9.394, de 20 de dezembro de 1996. 
- Em primeiro lugar, que o Estado necessita assumir sua responsabilidade na educação coletiva das crianças, complementando a ação das famílias.

- Em segundo lugar, creches e pré-escolas constituem-se em estratégia de promoção de igualdade de oportunidades entre homens e mulheres, uma vez que permitem às mulheres sua realização para além do contexto doméstico.

- Em terceiro lugar, cumprir função sociopolítica e pedagógica das creches e préescolas implica assumir a responsabilidade de torná-las espaços privilegiados de convivência, de construção de identidades coletivas e de ampliação de saberes e conhecimentos de diferentes naturezas, por meio de práticas que atuam como recursos de promoção da equidade de oportunidades educacionais entre as crianças de diferentes classes sociais no que se refere ao acesso a bens culturais e às possibilidades de vivência da infância.

- Em quarto lugar, cumprir função sociopolítica e pedagógica requer oferecer as melhores condições e recursos construídos histórica e culturalmente para que as crianças usufruam de seus direitos civis, humanos e sociais e possam se manifestar e ver essas manifestações acolhidas, na condição de sujeito de direitos e de desejos. Significa, finalmente, considerar as creches e pré-escolas na produção de novas formas de sociabilidade e de subjetividades comprometidas com a democracia e a cidadania, com a dignidade da pessoa humana, com o reconhecimento da necessidade de defesa do meio ambiente e com o rompimento de relações de dominação etária, socioeconômica, étnico-racial, de gênero, regional, linguística e religiosa que ainda marcam nossa sociedade (BRASIL, 2013, p. 85).

De acordo com as DCNEB, "a criança, centro do planejamento curricular, é sujeito histórico e de direitos que se desenvolve nas interações, relações e práticas cotidianas a ela disponibilizadas e por ela estabelecidas com adultos e crianças de diferentes idades nos grupos e contextos culturais nos quais se insere" (BRASIL, 2013, p. 86). Sendo assim, o espaço escolar deve ser pensado como lugar onde ela deseja, aprende, pergunta, tem contato com o ambiente, constrói amizades, estabelece conexões com o mundo, além do ambiente familiar. É necessário que a EI tenha um olhar cuidadoso às necessidades da criança, para que a alegria dos primeiros anos de escolarização perdure durante a longa caminhada na educação básica.

A criança, na etapa da EI, é um indivíduo em condições de múltiplas aprendizagens. Por meio de brincadeiras, interagindo com colegas de classe ou professores, demonstram curiosidade, observam, questionam e constrói saberes. Um "terreno fértil", que deve ter por parte dos educadores, um olhar atento para as diversas possibilidades de explorar as situações de aprendizagens, tornando-as significativas.

Nesse sentido, a busca pela construção de uma alfabetização científica deve iniciar desde os primeiros passos da educação básica, pois, conforme Chassot (2011), esta se constitui um conjunto de saberes que instrumentalizam homens e mulheres numa leitura facilitada do mundo, mas também os tornam capazes de intervir em suas realidades, atuando de forma crítica e transformadora. Compreender a alfabetização científica como um conceito muito além do conhecimento de um vocabulário científico permite ao educador perceber nas crianças, mesmo na EI, a possibilidade de compreender o mundo a sua volta, instigando a curiosidade natural inerente a essa faixa 
etária por meio das atividades lúdicas, leituras ou experimentos científicos adequados ao momento escolar.

Quando se aborda a formação de cidadãos com o espírito crítico, Krasilchik e Marandino (2007) sugerem que algumas competências são necessárias:

- Ter consciência da importância de sua função no aperfeiçoamento individual e das relações sociais;

- Ser capaz de expressar seus julgamentos de valor;

- Justificar suas decisões referindo-se a princípios e conceitos em que se basearam;

- Diferencial entre decisões pessoais de âmbito individual e decisões coletivas de âmbito público;

- Reconhecer e aceitar direitos, deveres e oportunidades em uma sociedade pluralista;

- Ouvir e aceitar diferenças de opiniões (KRASILCHIK; MARANDINO, 2007, p. 9).

A busca por um sujeito capaz de articular seus conhecimentos com seu papel cidadão deve perpassar por todo processo de escolarização, não integrando disciplinas específicas, mas constituindo-se das ações de cada ator presente na instituição escolar e fora dela. A aprendizagem envolvendo os jogos sociais necessários para o convívio se dá não apenas por meio de conteúdos, mas são expressos nas atividades, no "como" o professor resolve determinada situação-problema. Também perpassa ambientes de caráter não-formal e mesmo em outros contextos não educacionais.

Instrumentalizar o estudante, estimulando sua curiosidade, tornando-o apto a uma "leitura de mundo" em diferentes contextos bem como o auxiliar na construção de habilidades sociais constituindo um cidadão crítico e capaz de transformar a sua realidade é também papel da escola, em todos os seus níveis. Sendo assim, o incentivo ao espírito científico deve perpassar o ambiente escolar, instigando a criatividade e curiosidade infantil para a ciência que está à sua volta.

Dessa forma, esse artigo tem por objetivo apresentar um relato de uma experiência, envolvendo um grupo de crianças da EI, proporcionando o contato com atividades de caráter científico, com o intuito de promover à alfabetização científica e formação cidadã a partir dos primeiros anos de escolarização, desenvolvendo habilidades como linguagem, pensamento e sociabilidade. Também pretende-se apontar a importância do ensino de ciências na EI e reflexões sobre a formação de professores que atuam nessa etapa.

\section{EXPERIÊNCIA NA EDUCAÇÃO INFANTIL}

O relato dessa prática ocorrida na EI está marcado pela execução do estágio supervisionado obrigatório, disciplina pertencente ao curso de Licenciatura em 
Pedagogia. As três autoras já são licenciadas e atuantes no trabalho docente, porém, em áreas que as habilitam trabalhar em outros níveis do ensino formal ${ }^{5}$. A vivência na EI enquanto observadoras/docentes era inédita às três.

A participação das pesquisadoras na EI ocorreu em uma turma de Pré I, formada por dez estudantes, em uma escola da rede privada da região metropolitana de Porto Alegre, no RS. A chegada à escola ocorreu em um momento importante: o lanche.

A socialização entre as crianças foi evidente: durante o lanche coletivo, com duração aproximada de uma hora, eles contavam sobre suas famílias (pais, irmãos, avós) e suas travessuras. Questionaram-nos a respeito de muitos assuntos, mostrando o quanto são curiosos, sobre onde morávamos, como eram nossos alunos, etc. Explicamos que os acompanharíamos por alguns dias às suas aulas e que, no próximo encontro, faríamos uma atividade prática de ciências. A pergunta surgiu: "O que é ciências?". Explicamos que aprender ciências é compreender como a natureza funciona, nossa saúde e corpo, com outro significado. Para que entendessem melhor, relacionamos ao que faríamos em sala de aula, com os episódios que eles assistem do desenho animado "Backyardigans Cientistas”. A ideia foi recebida com aplausos e demonstrações de alegria.

No dia da aplicação da atividade, a receptividade à proposta superou as expectativas. A prática foi estruturada da seguinte maneira:

1) Eixo de trabalho e conteúdo: Ciências da Natureza - Sistema Digestório e Alimentos.

2) Objetivos: Reconhecer a importância da mastigação para a digestão dos alimentos, bem como, a função dos dentes na mastigação, ação do suco gástrico no estômago e a importância do amido na alimentação.

3) Materiais utilizados: meia de nylon transparente, bolinha de isopor, copo de Becker, leite, vinagre, bicarbonato de sódio, batata cozida, maçã, arroz cozido, laranja, pão, biscoito tipo água e sal, tintura de iodo.

A prática foi iniciada com a explicação da importância da mastigação, para a digestão. Mostramos uma figura que a dentição na faixa etária de cinco anos é constituída por cerca de 20 dentes, sendo esses chamados de dentes de leite e que serão substituídos naturalmente pelos permanentes, passando então, progressivamente, a formação de 32 dentes. Tratamos da necessidade do cuidado com os dentes, fazendo higienização e escovação correta.

5 As autoras são licenciadas em Química, Biologia e Matemática atuando, respectivamente, nestas áreas, na educação básica.

6 Desenho animado transmitido em um canal de televisão por assinatura brasileiro assistido por todos os estudantes da turma. 
Com a meia de nylon e a bolinha, demonstramos como os alimentos passam pelo esôfago e chegam até ao estômago. Essa primeira etapa foi simulada com eles, solicitando que mastigassem bem um pedaço de biscoito tipo água e sal e engolissem. Ao deglutir, deveriam colocar a mão no pescoço para sentir o movimento realizado no esôfago ao engolir o alimento.

Para simular o alimento no estômago com a ação do suco gástrico, colocamos em um copo de Becker uma colher de sobremesa de bicarbonato de sódio, pedaços do mesmo biscoito que realizamos a prática anterior com a turma e adicionamos vinagre. Os estudantes ficaram admirados com o fenômeno ocorrido, no caso o biscoito, sofrendo a ação do vinagre e bicarbonato de sódio, diluindo-se quase que totalmente.

$\mathrm{Na}$ sequência, explicamos que alguns alimentos têm uma substância chamada amido, que é um tipo de carboidrato que se transforma em açúcares no organismo e que, portanto, devemos ingerir esses alimentos de forma moderada, devido a quantidade calórica e a rápida absorção. Apresentamos vários exemplos de alimentos que são consumidos cotidianamente pelas crianças, para verificação com a aplicação de tintura de iodo, qual deles contém amido em sua composição: laranja, massa, arroz (ambos cozidos), batata, biscoito, pão, maçã. Com esses alimentos dispostos em uma bandeja, propomos que cada criança gotejasse solução de iodo sobre eles e observassem a reação química. Explicamos que os alimentos que mudassem a cor de marrom para roxo (violeta) identificariam a presença do amido e, então, saberíamos quais alimentos devemos ingerir de forma moderada, para mantermos uma alimentação balanceada. Embora se tratando de uma atividade prática simples, a atenção, curiosidade e participação das crianças foram significativas e relevantes. Ao término da atividade, todos souberam identificar quais alimentos apresentavam amido, pois identificaram pela troca da coloração do iodo e, a exemplo de suas conclusões: "profe, temos que comer mais frutinhas que pãozinho, nê?" (criança A); "se eu comer só pãozinho e biscoitinho vou ficar gordinho?" (criança B).

Com essas manifestações simples das crianças, ficou evidente que houve compreensão da proposta. Com o fim do período de estágio, despedimo-nos dos pequenos, escutando aquilo que todo professor sonha escutar: "profes, quando vocês voltam?”. A partir dessa experiência na EI, foi possível a tessitura de algumas análises referentes ao ensino de ciências nos primeiros anos de escolarização assim como a importância da inserção das ciências, de maneira mais efetiva, na formação dos professores que atuam neste segmento.

Uma vez que as falas da professora e diretora da escola demonstram o interesse na proposta e vontade de saber fazer esse tipo de abordagem pedagógica: "Vou assistir à aula de vocês, porque adoro esse tipo de atividade, mas não aprendi isso na minha formação" (Professora R.); "Gurias, que bacana a proposta de vocês para os alunos. Eles vão adorar, gostam muito de novidades" (Diretora T.).

A abordagem de temas científicos de forma lúdica e interdisciplinar é imprescindível ao aprendizado nessa fase da escolarização. Todavia, se faz necessário refletir sobre 
a formação dos docentes atuantes na EI. Apresentamos algumas reflexões ancoradas em teóricos que sustentam essa proposta de ensino e aprendizagem favorecendo a alfabetização científica.

\section{ENSINO DE CIÊNCIAS NA EDUCAÇÃO INFANTIL}

É explorando o seu entorno que a criança vai conhecendo o mundo. Aprende a pensar, constrói concepções a partir do que manipula. Esses conceitos são palavras com as quais ela irá ler o mundo (MORAES, 1998). À criança, em seus primeiros anos de vida, esse reconhecimento de mundo é proporcionado, basicamente, no convívio familiar e no ambiente de escola. Atualmente, é permitida à criança frequentar a escola em uma jornada de no mínimo quatro horas, ou em tempo integral, com duração igual ou superior a sete horas (BRASIL, 2013). Ou seja, é possível que a criança permaneça mais tempo socializando na escola do que com a família, visto que, em muitas situações, o educando é levado ainda "dormindo" à escola e, quando retorna para casa, já está cansado da rotina de atividades do dia. A preocupação da escola na realização de atividades variadas, privilegiando diferentes estímulos se torna fundamental para o desenvolvimento infantil.

O aprendizado nesta faixa etária é realizado progressivamente, em meio às atividades lúdicas como brincadeiras, jogos e estímulos à oralização e expressão corporal. Dessa forma, a criança vai, paulatinamente, adquirindo familiaridade com as diferentes linguagens para a leitura de mundo. As atividades também permitem a formação gradativa de habilidades que auxiliam na construção de um sujeito crítico capaz de atuar e transformar em diferentes contextos na sociedade.

Conforme Chassot (2003, p.91), a ciência também constitui uma linguagem e, sendo assim, alfabetizar-se cientificamente é "saber ler a linguagem em que está escrita a natureza”. A alfabetização científica pode ser proporcionada por meio de diferentes recursos, como leituras para o grupo, vídeos, estímulos a questionamentos, experimentos práticos integram o conjunto de conhecimentos a serem adquiridos ainda no início da escolarização. Pois, para Chassot (2003), a alfabetização científica constitui uma das facetas potencializadoras para uma educação mais comprometida.

O desenvolvimento humano, segundo Vygotsky (1989), está embasado na mediação, que são norteadas pela representação mental que permite ao indivíduo estabelecer relações mentais e as representações simbólicas que possibilitam desenvolvimento da abstração e generalização. De acordo com esse teórico, a mediação desse processo se dá pelo que ele denomina de Zona de Desenvolvimento Proximal. Essa se constitui pelo nível de conhecimento real, aquilo que a criança traz de saberes do seu cotidiano, o que ela sabe realizar sozinha e o nível de desenvolvimento potencial, que considera o que a criança faz com a mediação de um adulto. Ao propor uma atividade prática de ciências às crianças da EI, tem-se por objetivo tornar o abstrato em concreto, construindo as relações mentais do que eles já sabem e vivenciam em conhecimento elaborado, por 
meio de intervenções pedagógicas. Portanto, o desenvolvimento real será realizado e mediado pelo professor, transformando em desenvolvimento potencial. A aprendizagem ocorre desde o nascimento da criança e seu desenvolvimento se dá pela interação do meio em que vive (VYGOTSKY, 1989). Logo, o aprender ciências será possível se a criança tiver interação com essas ensinagens.

O conhecimento científico deve estar presente nas propostas de sala de aula, desde os primeiros anos escolares. Weissmann (1993) reconhece que a formação científica das crianças contribui para a formação de futuros cidadãos que sejam responsáveis pelos seus atos individuais e coletivos. Esse saber científico é uma inegável responsabilidade da escola, quando propõe a alfabetização científica. Não querermos com isso dizer que essa criança deverá tornar-se cientista, mas sim, ter conhecimentos científicos que serão importantes em sua formação como cidadão. É importante salientar que na a conotação de alfabetização não é sinônimo de letramento. De acordo com Soares (1998), alfabetização pode ser compreendida relacionada ao ensino da leitura e escrita, enquanto letramento, requer não apenas saber ler e escrever, mas envolve a prática social.

Equivocadamente, muitos educadores creditam a pouca idade das crianças na EI, a impossibilidade de aprender ciências, por ser abstrata, complexa e difícil. Na contramão dessa teoria, sabemos que a criança tem capacidades cognitivas já desenvolvidas que the permitem aprender ciências com uma linguagem simples. Portanto, o ensino de ciências na EI, é relevante, tendo em vista o que apresenta Colinvaux (2004, p. 107):

\footnotetext{
Em uma perspectiva mais propositiva, articulamos uma proposta de educação em ciências que destaca as dimensões de experiência, linguagem e conhecimento, com uma discussão da gênese psicológica da experimentação, para concluir que uma iniciação às ciências para crianças pequenas é possível.
}

Para que o ensino de ciências seja significativo à criança é interessante que ele parta de conhecimentos que essa já possui e que as novas descobertas a incentivem a querer apreender, adquirir novos saberes. Se a sala de aula é um espaço socialização e novas aprendizagens desde a EI, a curiosidade em novas descobertas e as diferentes experiências deverão estar ancoradas nas propostas de sala de aula, no que a professora ou o professor irá elaborar. Exige, portanto, que o docente busque novas formas de trabalhar na EI, incluindo o ensino de ciências e a iniciação científica desde a mais tenra idade, oportunizando o desenvolvimento de habilidades que poderão facilitar a compreensão das ciências em fases posteriores do ensino e, quem sabe, motivar essas crianças a uma futura profissão. Essa responsabilidade em desenvolver capacidades é da escola e "ser professora de ciências consiste em ser junto com os alunos, uma pesquisadora, curiosa e ativa” (MORAES, 1998, p.17). 


\section{FORMAÇÃO DE PROFESSORES DA EDUCAÇÃO INFANTIL: ENSINAR CIÊNCIAS É POSSÍVEL}

Para ensinar ciências na EI é imprescindível criatividade didática e metodologia. Todos os espaços e momentos na escola são pertinentes à aprendizagem dessa área do conhecimento: a sala de aula, o pátio da escola, a pracinha, a hora do lanche, a higienização e outros. De acordo com Moraes, (2007, p.30): "Aprender ciências é abrir uma nova janela para a compreensão do mundo, dominar uma nova linguagem, conseguir empregar novas palavras ou usar as antigas com novos significados".

Liberali (2008, p. 26) afirma que,

Entende-se que é abstraindo os conceitos cotidianos (individuais e não conscientes) sobre a própria prática de ensino-aprendizagem através de sua relação com a teoria formal (conceitos científicos, ou seja, abstrações hierarquizantes dadas pela cultura), que haverá possibilidade de consciência do próprio fazer pedagógico num sentido mais amplo. Entender estes conceitos científicos possibilita uma revisão da própria ação, seu questionamento e transformação aplicada, uma vez que parte da realidade concreta do sujeito, abstrai teoricamente através da voz de outros e redimensiona internamente para criar externamente.

E o professor se pergunta: como fazer? O que fazer?

O como fazer na EI é imprescindível que o lúdico esteja presente nas propostas. A criança brincando aprende potencialmente e esse aprendizado ganha sentido. Além da ludicidade, a atividade deve contemplar assuntos que são do seu cotidiano, que eles já tenham algum conhecimento. Com isso, a criança será cativada para o aprender. $\mathrm{O}$ uso correto da linguagem também deve ser considerado pelos professores, pois usar uma linguagem simplificada para que a criança compreenda não significa usar "apelidos" ou inventar nomes.

As habilidades científicas permitem à criança desenvolver-se intelectualmente, e isso será uma contribuição significativa para suas compreensões e aprendizagens futuras, não apenas em ciências, mas em todas as áreas do conhecimento, inclusive, em sua construção cidadã. Numa proposta que apresente diferentes situações de aprendizagem, encorajando os participantes a expressar o que observam e o que aprendem e o professor esteja mediando suas percepções e conclusões, certamente será mais significativo o aprendizado.

Nas conversas informais que tivemos com as professoras da escola de EI em que aconteceu nossa experiência, percebemos em suas falas, que "trabalhar ciências" não é uma prática comum ${ }^{7}$, pois não se sentem habilitadas para trabalhar esses conteúdos. Os trabalhos realizados pelas docentes consistem, basicamente, em temas envolvendo

7 Inclusive no Projeto Político Pedagógico (PPP) e Regimento da Escola, não há menção à Educação Científica. 
cuidados de higiene e doenças sazonais (como a gripe H1N1) e com relação ao meio ambiente, a separação dos resíduos sólidos.

Nesse sentido, Imbernón (2009, p. 12) trata da preocupação dos professores em seu processo de formação quando escreve:

\begin{abstract}
A inquietude por saber como, de que modo, com quais pressupostos, com que modelos, quais modalidades formativas podem gerar maior inovação e, sobretudo, a consciência de que o que pretendemos saber deve ser revisto e atualizado à luz dos tempos atuais, trata-se de uma preocupação bem mais recente.
\end{abstract}

Essa inquietação que alguns professores sentem em o que fazer? ocorre porque não tiveram uma formação específica para tal e isso pode conter um aspecto positivo, uma vez que os move em busca de novos saberes docentes. Para tanto, há necessidade das instituições públicas e particulares que atuam com a EI promover formação continuada aos professores. Ou mesmo, instituições de nível superior, em seus cursos de Pedagogia, por meio de pesquisas colaborativas (TARDIF, 2006), abraçarem a ideia de fomentar o ensino de ciências na EI. Também, deve-se refletir na incompletude dos cursos de formação, nunca abarcando todas as possibilidades e necessidades de um professor em sua atuação docente. Cabe a esse profissional a busca pela complementação às suas carências, de forma voluntária e individual, a fim de atender e melhorar sua prática pedagógica.

Perrenoud (2002) e Nóvoa (1992) concordam que o educador reflexivo faz de sua ação uma constante mudança, que lhe dá condições de aprender com a sua própria prática. Nesse sentido, a formação docente pela pesquisa seria uma maneira de proporcionar a esse profissional a sua constante ação-reflexão, para reestruturar a sua prática e atingir os níveis de excelência desejados e esperados na educação.

Certamente isso traria benefícios a médio e longo prazo à educação de modo geral, em especial, ao ensino aprendizagem de ciências. Pois em pleno século 21, muitos ainda têm a ideia equivocada que fazer ciências é só para cientistas. Isso se deve, em grande parte, ao fato de que a escola enquanto formadora e nós professores agentes dessa formação, não desmistificamos esse olhar sobre as ciências. Este paradigma em que a ciência é vista como algo inacessível e difícil precisa ser modificado e, cabe aos educadores, desde a EI, mostrar a sua importância e possibilidades de aprendizagem.

\title{
CONSIDERAÇÕES FINAIS
}

Como sujeitos da aprendizagem, somos seres inacabados em que sempre teremos algo a aprender, a descobrir. Essa ideia é válida para professores e alunos, independentemente do nível de ensino, uma vez que o convívio e a experiência com o outro no cotidiano escolar trazem novas aprendizagens e agregam conhecimentos. 
O que se precisa enquanto educador é estar aberto ao novo, refletir sobre suas ações e buscar aprimorar suas práticas.

No tocante à proposta realizada em decorrência ao estágio supervisionado, mencionamos alguns aspectos que consideramos relevantes. Primeiro deles a oportunidade de interagir com crianças tão pequenas e, com isso, descobrir o potencial cognitivo que delas emerge de forma latente. Segundo, que embora já graduadas, na área das ciências exatas e da natureza e em licenciatura, não havíamos tido contato com as a EI e saber o quão instigante pode se dar uma abordagem de iniciação científica às crianças, que ainda não foram alfabetizadas foi muito gratificante, motivador e, com certeza, nos dará subsídios para outros trabalhos dessa natureza.

É fundamental que os professores tenham capacitação, na formação inicial ou continuada, que os permita atuarem de forma mais significativa no ensino de ciências da EI. Para isso, se faz necessário que estes profissionais vislumbrem a importância das ciências não apenas como uma matéria escolar, mas como um instrumento para a compreensão e "leitura de mundo". O conhecimento científico não se encerra em um vocabulário rebuscado, mas na compreensão e atuação do sujeito na busca por soluções a problemas reais do seu cotidiano. Sendo assim, ressalta-se a importância do professor também se perceber como figura atuante na construção do sujeito crítico por meio de suas ações e decisões no momento do seu planejamento e prática docente.

Quem pode imaginar que essa simples prática de identificação de amido nos alimentos, não tenha despertado um futuro profissional das ciências?

\section{REFERENCIAS}

BRASIL, Constituição da República Federativa do Brasil de 1988. Disponível em: < http:// www.planalto.gov.br/ccivil_03/constituicao/constituicao.htm> Acesso em 30 de maio de 2015.

, LDB: Lei de Diretrizes e Bases da Educação Nacional. Lei no 9.394, de 20 de dezembro de 1996, que estabelece as diretrizes e bases da educação nacional. Disponível em: http://www.planalto.gov.br/ccivil_03/leis/L9394.htm Acesso em 15 de agosto de 2016.

Diretrizes Curriculares Nacionais Gerais da Educação Básica. Ministério da Educação. Secretária de Educação Básica. Diretoria de Currículos e Educação Integral Brasília: MEC, SEB, DICEI, 2013.

BUJES, M.I.E. Escola Infantil: Pra que te quero? Artmed: Porto Alegre, 2001.

CHASSOT, A. Alfabetização Cientifica: uma possibilidade para a inclusão social. Revista Brasileira de Educação, n.22, 2003, p. 89-100.

Alfabetização Científica: questões e desafios para a educação. 5a ed. Ijuí: Editora UNIJUÍ, 2011.

CRAIDY, C.; KAERCHER, G.E. Educação Infantil - Pra que te quero? In.: BUJES, M.I.E. Escola Infantil: Pra que te quero? Artmed: Porto Alegre, 2001.p. 13-22 
COLINVAUX, D. Ciências e crianças: delineando caminhos de uma iniciação às ciências para crianças pequenas. Contrapontos - vol.4 - n. 1, Itajaí, jan./abr. 2004. p. 105-123.

IMBERNÓN, F. Formação Permanente do professorado novas tendências. $1^{\mathrm{a} e d . ~ S a ̃ o ~}$ Paulo: Cortez, 2009.

KRASILCHIK, M; MARANDINO, M. Ensino de Ciências e Cidadania. 2a ed. São Paulo: Moderna, 2007.

LIBÂNEO, J. C.; OLIVEIRA, J. F.; TOSCHI, M. S. Educação Escolar: Políticas, Estrutura e Organização. 10a ed. São Paulo: Cortez, 2012.

LIBERALI, F. C. Formação crítica de educadores: questões fundamentais. Taubaté/SP: Cabral Editora e Livraria Universitária, 2008.

MORAES, R. Ciências para as séries iniciais e alfabetização. $3^{a}$ ed. Porto Alegre: Editora Sagra Luzzato,1998

Aprender Ciências: reconstruindo e ampliando saberes. In.:

GALIAZZI, M. do C.; AUTH, M.; MORAES, R.; MANCUSO, R. Construção

Curricular em Rede na Educação em Ciências: uma aposta de pesquisa em sala de aula. Ijuí: Ed. Unijuí, 2007.p. 19-38.

NÓVOA, A. Os professores e a sua formação. 1992. Disponível em: <http://repositorio. ul.pt/bitstream/10451/4758/1/fdp-a-novoa.pdf.> Acesso em 15 nov. 2015.

PERRENOUD, P. A prática Reflexiva no Ofício do Professor: profissionalização e razão pedagógica. Porto Alegre: Artmed, 2002.

SOARES, M. Letramento: um tema em três gêneros. Belo Horizonte: Autêntica, 1998.

TARDIF, M. Saberes docentes e a Formação Profissional. 7. ed. Petrópolis: Vozes, 2006.

VYGOTSKY, L. S. Pensamento e Linguagem. 2a ed. São Paulo: Martins Fontes, 1989.

WEISSMANN, H. Didácticas especiales. Bueno Aires: Aiqué, 1993. 